\title{
Determining the tribological features of concrete and assessing the service life of architectural facilities
}

\author{
Rebeca Martínez García ${ }^{1}$, Anton Kharitonenkov², Oleg Kuzmin ${ }^{3}$, Vera Snezhko ${ }^{4}$ \\ ${ }^{1}$ Department of Mining Technology, Topography and Structures, University of León, León, Spain \\ ${ }^{2}$ Department of 316 Systems Modeling and Computer-Aided Design, Moscow Aviation Institute (National \\ Research University), Moscow, Russian Federation \\ ${ }^{3}$ Department of Technology of Building Materials and Metrology, Saint Petersburg State University of \\ Architecture and Civil Engineering, Saint Petersburg, Russian Federation \\ ${ }^{4}$ Department of Information Technology in APC, Russian State Agrarian University - Moscow Timiryazev \\ Agricultural Academy, Moscow, Russian Federation \\ ${ }^{3}$ Corresponding author \\ E-mail: ${ }^{1}$ martinezgarciar5@yahoo.com, ${ }^{2}$ akharitonenkov@rambler.ru, ${ }^{3}$ ol.kuzmin@rambler.ru, \\ 4ver.sn8695@rambler.ru
}

Received 3 August 2021; received in revised form 4 October 2021; accepted 17 October 2021 DOI https://doi.org/10.21595/jme.2021.22167

Check for updates

Copyright $(C 2021$ Rebeca Martinez Garcia, et al. This is an open access article distributed under the Creative Commons Attribution License, which permits unrestricted use, distribution, and reproduction in any medium, provided the original work is properly cited.

\begin{abstract}
The construction industry is increasingly striving to improve the tribological features of architectural structures to increase their service life. The focus lies on self-compacting concrete (SCC) as the most appropriate option to fulfil this task. However, there are still some problems related to its durability, particularly in terms of physical and chemical properties, which are crucial in preventing corrosion of the reinforcement. This study seeks to assess the durability of self-compacting concrete and C20/25 class concrete with similar compressive strength. The measurements taken during the study include the primary strength indicators (water porosity, chloride diffusion, and oxygen permeability) and additional properties necessary for a better understanding (mercury porosity, capillary water absorption, carbonation, and ammonium nitrate leaching). Mixes of SCC and conventional concrete contained the same raw materials in identical proportions. Test results revealed that the service life of these two concretes could be considered equivalent. Therefore, self-compacting concrete with specific compressive strength can be regarded as durable as shock concrete. The scientific novelty of the study lies in the measurement of durability properties and the service life of concrete structures taking the coefficient of friction on a steel plate for the purpose of comparing concretes with equivalent compressive strength.
\end{abstract}

Keywords: self-compacting concrete, tribometer, friction coefficient, permeability, durability, compressive strength.

\section{Introduction}

Concrete is among the primary and most widely used materials in the construction industry. Due to its strength and fluid consistency, concrete can be used to embody bold and complex design ideas. Therefore, it is imperative to develop new and improve the existing ways of enhancing concrete properties. Besides the strength of hardened concrete, it is necessary to consider the tribological characteristics of fluid concrete, which directly affect the formwork design [1]. The past decade saw a rise in the popularity of self-compacting concrete (SCC). This type of concrete is a flowable mixture that has the ability to compact under its own weight and fill the space between the formwork and reinforcement bars without the use of external compaction forces (no vibration) [2-4]. Using SCC removes the requirement of additional vibration and thus reduces the construction time and costs. It can be placed easily in formwork and reinforcement. The introduction of SCC promoted the development of the construction industry. Meantime, there is a need to explore its mechanical properties and how they affect the formwork. The French Standard [5] recommends that the hydrostatic thrust of the material is considered when designing forms to ensure their safety. 
SCC has the following advantages: faster construction and higher strength of the building structure; fewer defects; no separation of materials; strong bonding with reinforcement; penetration into hard-to-reach places; long lifespan; absence of noise and vibrations, safe installing, and more [6]. The disadvantages of using SCC include high cost and high creep coefficient [7].

Even though it is expensive, SCC is very popular because of its unique properties. For example, the ultimate tensile strength of some SCC is higher than that of a simple concrete composition [8]. SCC with an adequate cement/water ratio exhibits good tribological behaviour [9]. The elasticity of SCC is $15 \%$ lower compared with conventional cement-sand mixes. The reduction in elasticity is due to the presence of fine aggregates (ash and sand) in the formulation, combined with small amounts of coarse stone particles [10]. Due to their advantages, these mixtures are widely used in complex building structures.

This study focuses on the sustainability of the architectural structures built using SCC. Since its first use in Japan in the late 1980s [1], SCC has been increasingly employed in commercial and prefabricated mixtures to enhance some aspects of construction.

The workability of SCC depends on many factors, such as water/cement ratio, mixture stability, rheology, and so forth [11]. At the same time, SCC exhibits a certain tendency for cracking, which depends on the capillary pressure build-up rate [12], concrete friction against the formwork walls [7], and the process of concrete setting. The quality of the structure also depends on mixture consistency and starting materials, which affect the colour, structure homogeneity, and surface smoothness of the hardened structure. Other factors influencing these qualities are associated with the type of the formwork and its removal.

When exploring the dynamic relationship between concrete and formwork, it is crucial to consider the lateral pressure on formwork after the concrete is poured. These data must be taken into account when designing the formwork structure. The lateral pressure of conventional concrete was reported to gradually decrease and become zero within 3 to 3.5 hours after the concrete is poured $[13,14]$. With SCC, the reduction dynamics of lateral pressure can differ significantly, not to mention that it depends on the casting depth. Knowing the pace of lateral pressure reduction allows planning the placement of casting sites and the formwork assembly. Aside from that, it is vital to know the time it takes to reach the full compensation of lateral stress to plan the further use of the formwork [15].

During the study, the following durability properties were considered: water porosity, chloride diffusivity, oxygen permeability, and portlandite content. Additional indicators were mercury porosity (considered equivalent to water porosity), capillarity water absorption, carbonation and ammonium nitrate leaching.

\section{Literature review}

Many experimental studies have been devoted to lateral formwork pressure by conventional and self-compacting concrete, and the results of those studies are at the heart of several theoretical models. Early models for assessing tribological properties of fresh concrete and their effect on lateral pressure were based on the principles of soil mechanics [16], which work well for conventional concrete materials. Models for SCC [17-19] are based on soil mechanics to describe the effect of fresh concrete on formwork. Vanhove et al. [17] used silo geometry to construct their pressure model, in which fresh concrete was taken as a continuous granular medium. The assumption was that concrete and formwork were in perfect frictional contact. The lateral pressure on formwork $P^{\prime}(H)$ (Fig. 1) can be determined by the following formula:

$P^{\prime}(H)=\frac{\rho g e L-\tau_{0}(2 e+2 L)}{f \mu(2 e+2 L)(1-\sin \varphi)} \times\left(1-\exp -\frac{f \mu(2 e+2 L)(1-\sin \varphi)}{e L} H\right)$,

where: $\rho$ is concrete density, $\tau_{0}$ is yield strength, $g$ represents gravitational acceleration, $e$ is a 
distance between formwork surfaces, $L$ represents formwork width, $H$ represents formwork height, $\varphi$ is internal friction angle, $\mu$ is the coefficient of friction between formwork and concrete, and $f$ is friction coefficient describing particle-particle and concrete-wall relationships.

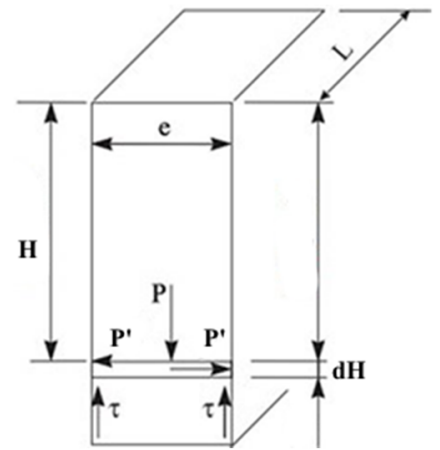

Fig. 1. Schematic representation of stress distribution in the formwork [17]

The results of tribological measurement show good agreement with the proposed model. The coefficient of friction varies from 0.15 to 0.35 for SCC from the top to the bottom of the formwork [17]. If the coefficient of friction for concrete against the wall $(\mu)$ is known, Eq. (1) can be used to estimate lateral formwork pressure exerted by fresh concrete.

To estimate the formwork pressure of SCC, Russell and Ovarlez [18] suggested a model integrating the yield stress $\left(\tau_{o}\right)$, assuming that SCC would behave as an elastic material at stress below the yield stress. Unlike the model offered by Vanhove et al. [17], this solution estimates the normal pressure on formwork walls without describing the proportionality between vertical and radial stresses. In addition, this model is in good agreement with experiments on SCC having standard air content; in other cases, admixtures may be required. At the same time, this model also has its limitations associated with simplifications and approximations that were made to ignore external factors. The model that takes those factors into account is Graubner's model [19], where the pressure exerted against the formwork depends on the casting velocity, the setting time of concrete, and the width of the formwork.

The above models describe the reduction dynamics of formwork pressure well. They require that the value of just one parameter (i.e., the coefficient of friction at the concrete/formwork interface) is known, established experimentally. Two latest studies with various fluid mixtures and pastes introduced new methods of measuring typological properties with the use of modified tribometers $[20,21]$. These instruments are also widely used to measure the coefficient of friction between formwork and fluid concrete. The particular focus was the friction involved when the $\mathrm{SCC}$ is introduced into the formwork and parameters that could influence the shocks.

\section{Mission statement}

The literature does not seem to provide a complete answer to whether SCC is as strong as conventional concrete with compressive strength, especially in terms of physical and chemical properties. Few studies [22-24] partially answer this question, but they usually concern the high-performance concrete. Other studies yield results for low to medium compressive strength SCCs [25-27].

This paper aims to evaluate concrete with compressive strength of 20-70 MPa. The objectives of the study are (1) to examine the sources of concrete used in the construction to determine the service life of concrete structures; (2) to assess the durability of SCC and C20/25 with respect to their contents; (3) to evaluate plasticizing agents as admixtures for concrete products; (4) to compare the tribological properties of SCC and C20/25 concretes; and (5) to measure the coefficient of friction for concrete samples on steel with the TR210 device. 
The primary objective is to compare the durability properties of SCC and concrete with equivalent compressive strength. The paper also examines the effect of several parameters affecting the concrete/formwork wall (metal plate) friction ratio. These parameters are roughness, sliding velocity against the steel plate, normal pressure, and the nature of the dissolving agent at the concrete/metal wall interface.

The scientific novelty of the study lies in the measurement of durability properties and the service life of concrete structures taking the coefficient of friction on a steel plate for the purpose of comparing concretes with equivalent compressive strength. The durability properties are easily quantifiable parameters that seem essential for evaluating the service life of the concrete and concrete structures. Other crucial features are strength and water/cement ratio.

\section{Materials and methods}

For the study, SCC mixes were made according to the European standard technology [28] from the ingredients presented in Table 1 . Samples of C20/25 concrete were made for comparison according to EN 206-1 technology [29].

Table 1. Making SCC and Concrete $\mathrm{C} 20 / 25$

\begin{tabular}{|c|c|c|c|}
\hline \multicolumn{2}{|c|}{ SCC } & \multicolumn{2}{c|}{ C20/25 } \\
\hline Component & Quantity, $\mathrm{kg} / \mathrm{m}^{3}$ & Component & Quantity, $\mathrm{kg} / \mathrm{m}^{3}$ \\
\hline Portland cement & 350 & Portland cement & 350 \\
\hline Pozzolana & 200 & Water & 200 \\
\hline Water & $170-180$ & Sand (granularity 1-2.5 mm) & 800 \\
\hline Sand (granularity 0-2 $\mathrm{mm}$ ) & 650 & Crushed stone $(5-20 \mathrm{~mm})$ & 900 \\
\hline Fine crushed stone $(2-16 \mathrm{~mm})$ & 950 & Plasticizer & 10 \\
\hline Plasticizer & $2-4$ & Water-cement ratio & 0.57 \\
\hline Water/cement ratio & 0.5 & & \\
\hline
\end{tabular}

The last-generation polycarboxylate water-reducing agent (PCWRA) was used as a plasticizer for the SCC mixture (Fig. 2), whereas the poly naphthalene-based plasticizer (PNSP) was used for the $\mathrm{C} 20 / 25$ mixture. All concrete mixtures were prepared using a planetary mixer. Plasticizing admixtures were used in SCC and conventional concrete to obtain specific moisture content.

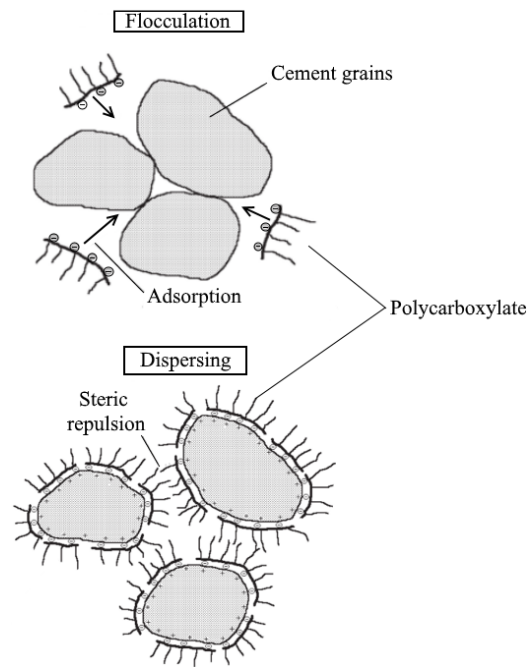

Fig. 2. Polycarboxylate water-reducing agent (PCWRA) for the SCC mixture

The tribological properties of concrete were measured using a tribometer (Figs. 3-4). This device enables the study of sliding friction, wear loss, and service life of the surface with varying 
time, pressure, velocity, temperature and humidity.

The principle behind tribological analysis was similar to that used with the kaolin paste [30]. The steel plate, driven by an electric motor, slides between concrete samples with a constant velocity, whereas a sensor measures the propulsive force (Fig. 3). A motor is linked to a screw. The rotating movement of the screw is transmitted to the screw/nut system where the tie transfers its movement to a plate. The plate is moved horizontally to minimize gravity. A saddle-mounted frame balances the pressures on both sides of the steel plate due to action and opposition. The plate moves $700-800 \mathrm{~mm}$. The contact pressure can be up to $1800 \mathrm{kPa}$, and the sliding velocity is around $300 \mathrm{~mm} / \mathrm{s}$.

The normal pressure transducer located between the thruster rod and the piston shows the pressure exerted by the thruster on the piston. The link between friction strength and normal stress makes it possible to obtain the coefficient of friction. The friction stress (tangential stress) was calculated according to the following formula:

$\tau_{f}=\frac{F_{m}-F_{p a r}}{S}$

where $F_{\text {par }}$ is the equilibrium friction force due to the watertight system relative to the plate. The contact area between the concrete and the plate $\left(S=115 \mathrm{~cm}^{2}\right)$ is calculated according to the diameter of the sample holder.

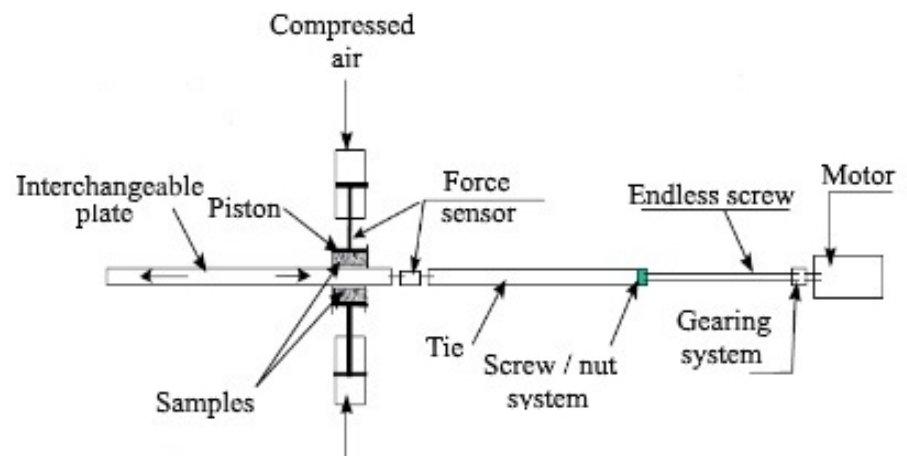

Fig. 3. The principle of the tribometer [17]

The principle behind the experimental setup (Fig. 4) is as follows: A concrete sample is pressed against a moving steel plate cut from the formwork wall. The concrete is fed to cylindrical sample holders with a diameter of $120 \mathrm{~mm}$ through a hole and pressurized using pneumatic jacks. A sealing system is mounted on the sample holders to seal concrete samples without damaging the oil film applied to the steel plate. A system of gaskets is installed on the sample support to prevent water leaks. A sliding bottom transfers the pressure applied by the $(N)$ pneumatic jack to the concrete [30].

For each test, the friction force was recorded at different time points. This force corresponds to two separate friction forces: $(1)$ the product of the interference friction force $\left(F_{\text {par }}\right)$ generated by the gasket system against the steel plate and the tie against the slide; and (2) the product of the tangential friction force $\left(F_{m e s}\right)$ produced by both concrete samples against the plate.

The average surface roughness was determined for both sides of the steel plate using the TR210 portable roughness meter (Fig. 5). The TR210 meter measures four basic surface roughness parameters $\left(R_{a}, R_{z}, R_{y}, R_{q}\right)$. The measurement results show that the maximum height of the profile $\left(R_{z}\right)$ varies from 5 to $29 \mu \mathrm{m}$. The average value of $R_{z}$ is $9 \mu \mathrm{m}$. The arithmetic mean deviation of the profile $\left(R_{a}\right)$ ranges between 0.8 and $1.9 \mu \mathrm{m}$. These values were obtained for two surfaces: (a) $R_{a}=0.35 \mu \mathrm{m}$; (b) $R_{a}=1.65 \mu \mathrm{m}$. Some parameters and measurement ranges used in the experiments are given in Table 2. 


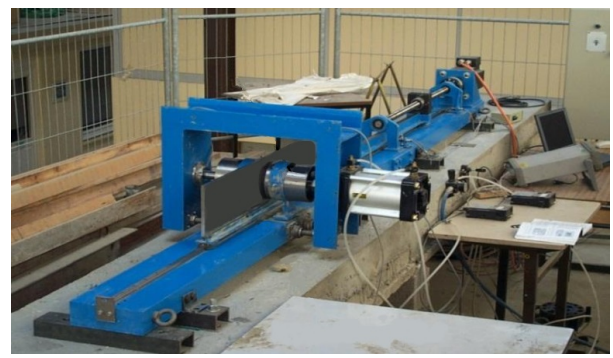

Fig. 4. Photograph showing the experimental setup (tribometer) with concrete samples and a steel plate [30]

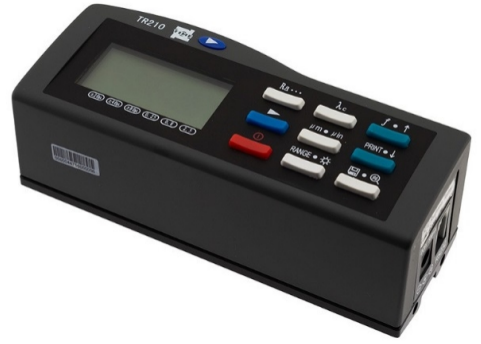

Fig. 5. The TR210 portable roughness meter with a graphic display

The velocity of the motor was measured with a Danaher AKM22C decoder rated $0.57 \mathrm{~kW}$. It was maintained constant via a feedback loop with a Servostar 300 electric drive with a rated speed of $8000 \mathrm{rpm}$ and an accuracy of $1 \%$. The friction force was measured with a KISTLER 9217A piezoelectric sensor and a KISTLER 5018A amplifier. The measured data were processed using Origin 8.0 Pro software.

Table 2. Boundary conditions for the experiment

\begin{tabular}{|c|c|c|c|}
\hline Variable & Range & Variable & Range \\
\hline Concrete placement rate & $0.5-1\left(\mathrm{~m}^{3} / \mathrm{h}\right)$ & Accretion rate & $0.5-50 \mathrm{~mm} / \mathrm{s}$ \\
\hline Formwork lifting speed & $1-25(\mathrm{~mm} / \mathrm{s})$ & Pressure rate & $35-500 \mathrm{kPa}$ \\
\hline SCC pressure (at $12 \mathrm{~m})$ & $195 \mathrm{kPa}$ & & \\
\hline
\end{tabular}

The stability of concrete mixtures was assessed by examining their physical-chemical and tribological properties. For this, different techniques can be used. French Association of Civil Engineering (AFGC) recommends chloride diffusion, water porosity and oxygen permeability [27].

Water porosity was determined by weighing the samples while they were in varying aggregation states. The formula is:

Water porosity $=\rho_{w} \frac{m_{a}-m_{d}}{m_{a}-m_{w}} \times 100 \%$,

where: $m_{a}$ is the mass of the sample weighed in air, $m_{d}$ is the mass of the dried sample, $m_{w}$ is the mass of the sample weighed in water, and $\rho_{w}$ is the density of water.

Chloride diffusion was measured using the diffusion method under the electric field [26]. For this, an external electric field of $10 \mathrm{~V}$ was applied to a concrete specimen saturated with an aqueous chloride solution. The current-voltage characteristics of the concrete specimens were studied to determine resistivity. The diffusion coefficient was calculated using the following formula:

$D_{C l}=D_{w} \frac{R_{w}}{R_{c}}$

where: $D_{w}$ is the diffusion coefficient of chlorides in water $\left(1.23 \cdot 10-5 \mathrm{~cm}^{2} / \mathrm{s}\right), R_{w}$ is the specific resistance of an aqueous chloride solution $(\mathrm{Ohm}-\mathrm{cm})$, and $R_{c}$ is the specific resistance of saturated concrete.

Oxygen permeability was measured on a TQD-G1 Air Permeability Tester [31]. Capillary absorption was measured by assessing the absorption of fluid in a dry concrete mixture. For this, a dry mixture of concrete was pressed into cubic samples and immersed in a methanol solution (by $5 \mathrm{~mm}$ ), and absorption was measured at a constant temperature. 


\section{Results}

The present study focuses on measuring the coefficient of friction against a steel plate for SCC and $\mathrm{C} 20 / 25$ samples with varying surface roughness. The results of the measurement are depicted in Fig. 6. As can be seen, the coefficients of friction and their behaviour vary depending on contact pressure. When the roughness is low (a), the metal surface is more even, and the concrete does not flow into the void space. Therefore, the lower the surface roughness, the lower the coefficient of friction. However, when the roughness is higher (b), different-sized particles can get stuck to surface protrusions, resulting in more pressure. In addition, the value of the particle size (sand and crushed stone) also affects friction.

Fig. 6 shows that SCC has higher than C20/25 coefficients of friction. The reason is the presence of smaller and more uniformly dispersed particles within the formulation. Smaller particles can penetrate the voids of the plate, causing more impact. It is especially noticeable with high contact pressures (up to $150 \mathrm{kPa}$ ).

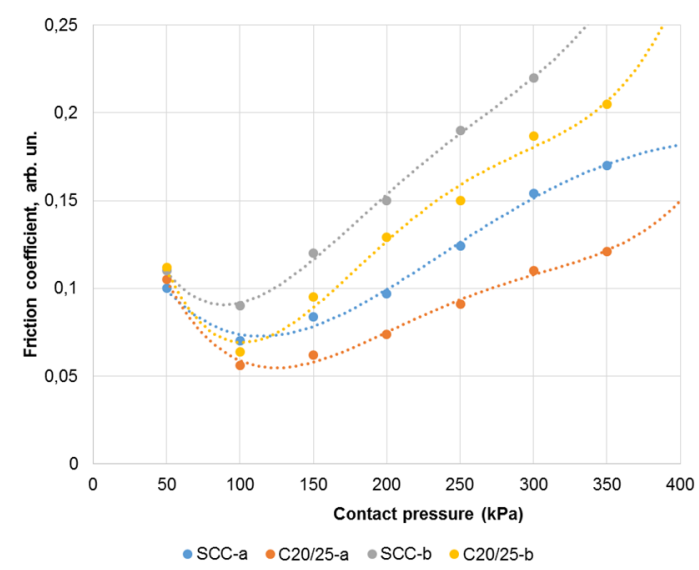

Fig. 6. The friction coefficient via contact pressure at a sliding speed of $2.5 \mathrm{~mm} / \mathrm{s}$ for SCC and C20/25 samples: (a) $R_{a}=0.35 \mu \mathrm{m}$; (b) $R_{a}=1.65 \mu \mathrm{m}$.

The lowest values of the friction coefficient were seen with a contact pressure of $150 \mathrm{kPa}$. Those values correspond to the minimum wear intensity from friction at $2.5 \mathrm{~mm} / \mathrm{s}$. A further decrease in pressure leads to a slight increase in deformation at the contact interface. This happens because, at low contact pressures, sand and crushed stone particles rotate, causing the metal to wear faster.

However, the value of the friction coefficient depends not only on contact pressure and particle size but also on the rate of friction. When the sliding velocity varies from 0.5 to $25 \mathrm{~mm} / \mathrm{s}$, part of the boundary layer becomes trapped in plate irregularities and flows into the grooves due to plate displacement under pressure. The grains trapped in the voids will then turn the concrete particles in contact with and near the wall, causing significant energy dissipation. This dissipation increases the friction coefficient and subsequently decreases when the velocity is more than $25 \mathrm{~mm} / \mathrm{s}$. In this case, sand and gravel particles flow faster between the voids with lower shear resistance, causing less damage to the metal surface at a contact pressure of $150 \mathrm{kPa}$.

The physicochemical properties of the studied concrete mixtures are presented in Table 3. As can be seen, SCC has $1.4 \%$ higher water porosity compared with $\mathrm{C} 20 / 25$, perhaps due to a higher water-to-cement ratio. Chloride diffusion data show that SCC and C20/25 have almost equal effective diffusion coefficients and are of the same magnitude order.

The values of oxygen permeability were obtained under $0.2 \mathrm{MPa}$ pressure. The rate of pore saturation was selected to assess the internal properties of concrete, even though it does not apply to concrete under normal operating conditions. Data in Table 3 show that C20/25 has higher than 
SCC oxygen permeability. Hence, C20/25 was more sensitive to the pretreatment method: microcracks from drying became more significant when compared to SCC. The values of capillary absorption are similar between SCC and conventional concrete. In addition, SCC has a $2.6 \%$ higher $\mathrm{Ca}(\mathrm{OH})_{2}$ carbon content compared to $\mathrm{C} 20 / 25$.

Table 3. The durability of concrete as per AFGC recommendations

\begin{tabular}{|c|c|c|}
\hline Durability properties & SCC & C20/25 \\
\hline Water porosity $(\%)$ & 11.5 & 10.1 \\
\hline Capillary absorption $\left(\mathrm{kg} / \mathrm{m}^{2}\right)$ & 2.9 & 2.7 \\
\hline Diffusion coefficient $\left(10^{-12} \mathrm{~m}^{2} / \mathrm{s}\right)$ & 1.8 & 1.9 \\
\hline Visible oxygen permeability $\left(10^{-18} \mathrm{~m}^{2}\right)$ & 49.8 & 59.9 \\
\hline $\mathrm{Ca}(\mathrm{OH})_{2}$ content $(\%$ of cement weight $)$ & 26.1 & 23.5 \\
\hline
\end{tabular}

\section{Discussion}

According to AFGC recommendations [5] for classifying the strength of the concrete, both concrete mixes examined exhibit high values of each sustainability indicator. The analysis of typological properties revealed that the wear intensity of the SCC under friction became higher with an increase in the contact pressure and contact surface roughness. However, an increase in the velocity of the mixture can impede this effect. When the concrete mix is conveyed through the pipes and poured into the form, its velocity is more than $25 \mathrm{~mm} / \mathrm{s}$. High velocity reduces friction against the walls and maintains the homogeneity of the fresh mixture and its uniformity during a pour $[16,32]$.

Mixing the aggregates into the cement paste makes the concrete stiffer to flow and improves its strength and elasticity properties. Admixtures also have a restricting effect on shrinkage and creep. However, the nature of the aggregates used in the concrete formulation can affect the result. Experiments revealed that recycled aggregate concrete outperformed the natural aggregate concrete in terms of water absorption thanks to higher porosity, but its density was less [33]. The water absorption of the coarse and fine recycled aggregates was reported to be almost 2-2.85 times higher compared to the natural ones, although their specific was less. The downside of using recycled aggregates is that they have low quality and low mechanical strength, and their crushing value is substantially higher than that of the natural aggregates.

According to the results of the physical-chemical analysis, the examined mixtures belong to the class of durable, highly stable concretes. Both samples had practically identical values of water absorption and chloride diffusion. It means that the raw materials had good corrosion resistance. At the same time, these mixtures exhibit different values of carbonation and oxygen permeability. Conventional concrete has a lower rate of carbonation. Hence, it may have lower water absorption compared to SCC. In addition, a lower rate of carbonation could be a function of lower porosity and finer microstructure [27, 34]. The difference between the two concretes can disappear with uniform particle size (sand and crushed stone). A lower value of oxygen permeability and a higher value of water absorption of SCC indicate the presence of a more uniform microstructure and uniform porosity. Such properties could stem from the smaller particle size of sand and gravel used in the formulation $[35,36]$.

\section{Conclusions}

Through tribological and physicochemical analysis, the present study established several mechanisms for assessing concrete stability. The self-compacting concrete appeared to have a higher coefficient of friction, which increased with increasing contact pressure and surface roughness. This behaviour is due to smaller particle sizes and higher uniformity of sand and crushed stone particles, which penetrate the voids of the metal surface and increase wear intensity. A critical contact pressure at which the concrete exhibits minimum shear deformation is $150 \mathrm{kPa}$. The same effect can be achieved by reaching a friction velocity of more than $25 \mathrm{~mm} / \mathrm{s}$. 
Evaluation of concrete stability revealed that SCC and conventional concrete could be classified as high-strength concretes. The maximum height of the roughness profile $\left(R_{z}\right)$ varied from 5 to $29 \mu \mathrm{m}$ with a mean of $9 \mu \mathrm{m}$. The arithmetic mean deviation of the profile $\left(R_{a}\right)$ ranged between 0.8 and $1.9 \mu \mathrm{m}$. These values were obtained for two surfaces: (a) $R_{a}=0.35 \mu \mathrm{m}$; (b) $R_{a}=1.65 \mu \mathrm{m}$.

The chloride diffusion and water absorption data show that these two concretes have practically identical diffusion properties. The results of the oxygen permeability assessment revealed that SCC was more resistant to air penetration than conventional concrete. Due to its fine structure and fine particle size, SCC has higher corrosion resistance. The present findings can help develop adequate solutions for concrete pouring needs and proper formwork structures.

\section{References}

[1] H. Li et al., "A review on the pumping behavior of modern concrete," Journal of Advanced Concrete Technology, Vol. 18, No. 6, pp. 352-363, Jun. 2020, https://doi.org/10.3151/jact.18.352

[2] M. Mehrinejad Khotbehsara, E. Mohseni, T. Ozbakkaloglu, and M. M. Ranjbar, "Retracted: durability characteristics of self-compacting concrete incorporating pumice and metakaolin," Journal of Materials in Civil Engineering, Vol. 29, No. 11, p. 04017218, Nov. 2017, https://doi.org/10.1061/(asce)mt.1943-5533.0002068

[3] I. E. Evgenevna, I. T. Evgenevna, and B. P. Viktorovich, "Analysis of the application of turbulence models in the calculation of supersonic gas jet," American Journal of Applied Sciences, Vol. 11, No. 11, pp. 1914-1920, Nov. 2014, https://doi.org/10.3844/ajassp.2014.1914.1920

[4] Bulat, Pavel V. Chernyshev, and Mikhail V., "Existence regions of shock wave triple configurations," International Journal of Environmental and Science Education, Vol. 11, No. 11, pp. 4844-4854, 2016.

[5] "NF P93-350, Formwork for Concrete Structures," (in French), 1989.

[6] I. Demir, Sevim, and E. Tekin, "The effects of shrinkage-reducing admixtures used in self-compacting concrete on its strength and durability," Construction and Building Materials, Vol. 172, pp. 153-165, May 2018, https://doi.org/10.1016/j.conbuildmat.2018.03.250

[7] R. Gaimster and N. Dixon, "Self-compacting concrete," Advanced Concrete Technology, Vol. 3, pp. 123, 2003, https://doi.org/10.1016/b978-075065686-3/50295-0

[8] P. L. Domone, "A review of the hardened mechanical properties of self-compacting concrete," Cement and Concrete Composites, Vol. 29, No. 1, pp. 1-12, Jan. 2007, https://doi.org/10.1016/j.cemconcomp.2006.07.010

[9] S. Manzi, C. Mazzotti, and M. Chiara Bignozzi, "Self-compacting concrete with recycled concrete aggregate: Study of the long-term properties," Construction and Building Materials, Vol. 157, pp. 582590, Dec. 2017, https://doi.org/10.1016/j.conbuildmat.2017.09.129

[10] M. M. Kamal, M. A. Safan, A. A. Bashandy, and A. M. Khalil, "Experimental investigation on the behavior of normal strength and high strength self-curing self-compacting concrete," Journal of Building Engineering, Vol. 16, pp. 79-93, Mar. 2018, https://doi.org/10.1016/j.jobe.2017.12.012

[11] A. Leemann, P. Nygaard, and P. Lura, "Impact of admixtures on the plastic shrinkage cracking of selfcompacting concrete," Cement and Concrete Composites, Vol. 46, pp. 1-7, Feb. 2014, https://doi.org/10.1016/j.cemconcomp.2013.11.002

[12] Y. T. H. Cu, M. V. Tran, C. H. Ho, and P. H. Nguyen, "Relationship between workability and rheological parameters of self-compacting concrete used for vertical pump up to supertall buildings," Journal of Building Engineering, Vol. 32, p. 101786, Nov. 2020, https://doi.org/10.1016/j.jobe.2020.101786

[13] J. Abdalhmid, "Drying shrinkage of self-compacting concrete incorporating fly ash," Ph.D. Thesis, University of Bradford, Bradford, 2019.

[14] D. A. Zimina, C. A. Zhapkhandaev, and A. A. Petrov, "Analysis of the effect of nanosilicates on the strength and porosity of cement stone," in Key Engineering Materials, Vol. 854, pp. 175-181, Jul. 2020, https://doi.org/10.4028/www.scientific.net/kem.854.175

[15] W. J. Hawkins et al., "Flexible formwork technologies - a state of the art review," Structural Concrete, Vol. 17, No. 6, pp. 911-935, Dec. 2016, https://doi.org/10.1002/suco.201600117

[16] K. H. Khayat and A. Omran, "State-of-the art review of form pressure exerted by self-consolidating concrete," Université de Sherbrooke, Canada, 2010. 
[17] Y. Vanhove, C. Djelal, and A. Magnin, "Prediction of the lateral pressure exerted by self-compacting concrete on formwork," Magazine of Concrete Research, Vol. 56, No. 1, pp. 55-62, Feb. 2004, https://doi.org/10.1680/macr.2004.56.1.55

[18] G. Ovarlez and N. Roussel, "A physical model for the prediction of lateral stress exerted by selfcompacting concrete on formwork," Materials and Structures, Vol. 39, No. 2, pp. 269-279, Aug. 2007, https://doi.org/10.1617/s11527-005-9052-1

[19] T. Proske and C. A. Graubner, "The influence of coarse aggregate shape on the properties of highperformance, self-compacting concrete," in Czasopismo Techniczne, Vol. 5, pp. 159-166, 2017, https://doi.org/10.4467/2353737xct.17.066.6423

[20] J. Duran, Partially Ordered Systems. New York, NY: Springer New York, 2000, pp. 63-64, https://doi.org/10.1007/978-1-4612-0499-2

[21] H. D. Le, G. de Schutter, E. H. Kadri, S. Aggoun, and P. Troch, "Centrifugal effects on coaxial cylinders concrete tribometer," in International Conference on Sustainable Built Environment for Now and the Future, Vol. 26, p. 27, Mar. 2013.

[22] J. D. Henschen, D. I. Castaneda, and D. A. Lange, "Formwork pressure model for self-consolidating concrete using a pressure decay signature," ACI Materials Journal, Vol. 115, No. 3, pp. 339-348, May 2018, https://doi.org/10.14359/51702183

[23] W. Zhu, J. Quinn, and P. J. M. Bartos, "Transport properties and durability of self-compacting concrete," in 2nd International Symposium on Self-Compacting Concrete, pp. 451-458, 2001.

[24] K. Audenaert and G. de Schutter, "Influence of moisture on the carbonation of self-compacting concrete," in Proceedings of the 6th CANMET/ACI International Conference on Durability of Concrete-Supplementary papers, pp. 451-465, 2003.

[25] B. Persson, "A comparison between mechanical properties of self-compacting concrete and the corresponding properties of normal concrete," Cement and Concrete Research, Vol. 31, No. 2, pp. 193 198, Feb. 2001, https://doi.org/10.1016/s0008-8846(00)00497-x

[26] "AFPC-AFREM, Durability of Concretes, from the Technical Days Recommended Methods for the Measurement of Quantities Associated with Durability," 1997.

[27] M. Valcuende and C. Parra, "Natural carbonation of self-compacting concretes," Construction and Building Materials, Vol. 24, No. 5, pp. 848-853, May 2010, https://doi.org/10.1016/j.conbuildmat.2009.10.021

[28] "EFNARC, The European Guidelines for Self-Compacting Concrete," European Project Group, 2005.

[29] "European Standard EN206-1, Part I. Concrete: Specification, Performance, Production and Conformity," 2004.

[30] Chafika Djelal, Yannick Vanhove, and Laurent Libessart, "Analysis of friction and lubrication conditions of concrete/formwork interfaces," International Journal of Civil Engineering and Technology, Vol. 7, No. 3, pp. 18-30, May 2016.

[31] S. Assié, G. Escadeillas, and V. Waller, "Estimates of self-compacting concrete 'potential' durability," Construction and Building Materials, Vol. 21, No. 10, pp. 1909-1917, Oct. 2007, https://doi.org/10.1016/j.conbuildmat.2006.06.034

[32] M. I. Sadykov, P. A. Blinov, and M. V. Nutskova, "Use of the water-swellable polymers (WSP) for wellbore stabilization in intensely fractured rock intervals," in E3S Web of Conferences, Vol. 266, p. 01013,2021 , https://doi.org/10.1051/e3sconf/202126601013

[33] S. R. Salimbahrami and R. Shakeri, "Experimental investigation and comparative machine-learning prediction of compressive strength of recycled aggregate concrete," Soft Computing, Vol. 25, No. 2, pp. 919-932, Jan. 2021, https://doi.org/10.1007/s00500-021-05571-1

[34] M. P. Bulat et al., "Ignition of lean and stoichiometric air-propane mixture with a subcritical microwave streamer discharge," Acta Astronautica, Vol. 150, pp. 153-161, Sep. 2018, https://doi.org/10.1016/j.actaastro.2017.11.030

[35] B. Krishna and P. Jagadeesh, "Strength and Durability assessment of binary blended Self-Compacting Concrete replacing partial sand with electronic plastic waste," International Journal of Innovative Technology and Exploring Engineering, Vol. 8, pp. 107-111, 2019.

[36] V. M. Boiko, V. P. Kiselev, S. P. Kiselev, A. N. Papyrin, S. V. Poplavskii, and V. M. Fomin, "Interaction of a shock wave with a cloud of particles," Combustion, Explosion, and Shock Waves, Vol. 32, No. 2, pp. 191-203, May 1996, https://doi.org/10.1007/bf02097090 


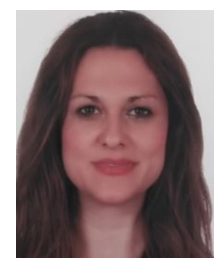

Rebeca Martínez-García is an Architect and Ph.D. in Biosystems Engineering. Lecturer at the University of León, among other topics in Graphic Expression in Engineering since 2013. Co-author of numerous articles in high impact scientific journals indexed in JCR, co-author in different international conferences and research projects, is member of the research unit Engineering of Materials and Eco-Efficiency (INMATECO). Director of project development and project management of more than 200 projects of Architecture and Engineering of new construction, rehabilitation, agro-industrial projects and public buildings. Her work has been published in such journals as Elsevier, Materials, and Applied Sciences.

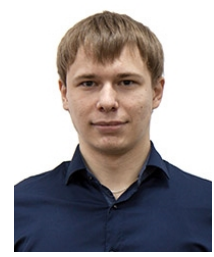

Anton Kharitonenkov is a senior Lecturer in the Department of Systems Modeling and Computer-Aided Design at the Moscow Aviation Institute (MAI). He began his professional career in 2013 as a computer graphics teacher in the Department of System Modeling and Engineering Graphics at the Moscow State Aviation Technology Institute (MATI). In 2015, by order of the Ministry of Education and Science of the Russian Federation, MATI merged with MAI. The Department was also reorganized, but continued to graduate students in Informatics and Computer Engineering. In 2019, Anton Igorevich obtained a postgraduate degree from the Moscow Aviation Institute. Currently, he continues his research in the field of computer-aided design and computer graphics.

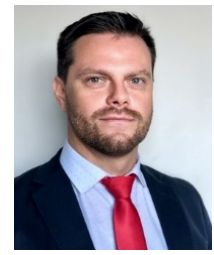

Oleg Kuzmin is a Candidate of Engineering Sciences (Ph.D.), Associate Professor at the Department of Technology of Building Materials and Metrology of Saint Petersburg State University of Architecture and Civil Engineering in Saint Petersburg, Russian Federation. His research interests include investigation of the influence of deformation, deformationthermal and thermal effects on the magnetic, structural and mechanical parameters of structural steels, development of methods for passive ferrazond monitoring and diagnostics of welded load-bearing metal structures of industrial buildings and technical devices, engineering education etc.

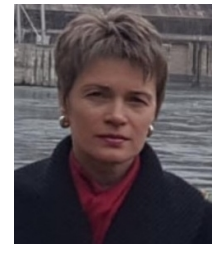

Vera Snezhko is a Doctor of Technical Sciences, Head of Chair at the Department of Information technology in APC of the Russian State Agrarian University - Moscow Timiryazev Agricultural Academy in Moscow, Russian Federation. Her research interests include computational fluid dynamics, numerical modeling of turbulent flows in nondeformable boundaries, pressure flow hydraulics, automation of hydraulic structures, systemic theory of GTS reliability, computer modeling of business processes, and applied statistics. 